\title{
SURVEY TURNED INTO HBIM: THE RESTORATION AND THE WORK INVOLVED CONCERNING THE BASILICA DI COLLEMAGGIO AFTER THE EARTHQUAKE (L'AQUILA)
}

\author{
D. Oreni, R. Brumana, S. Della Torre, F. Banfi, L. Barazzetti, M. Previtali
}

Department of Architecture, Built Environment and Construction Engineering, 20133 Milan, Italy (daniela.oreni, raffaella.brumana, stefano.dellatorre, fabrizio.banfi, luigi.barazzetti, mattia.previtali)@ polimi.it

\author{
Commission V
}

KEY WORDS: built heritage, 3D modelling, HBIM, interoperability, laser scanner, management, UAV

\begin{abstract}
:
The HBIM of the Basilica di Collemaggio in L'Aquila is part of the restoration project of the building seriously damaged by the earthquake in 2009. The project "Ripartire da Collemaggio", funded by ENIservizi, involves an interdisciplinary group called to work together toward a common goal: the need of security of the structures and the need of conservation of the architectonic value of the Basilica.

Starting from the photogrammetric and laser scanning survey, interpretation and modelling were needed to create a detailed HBIM to manage the phases of analysis, simulation of structural behavior, economic evaluation of the project, and final restoration. This paper described the generation of the HBIM and its use in the on-going restoration project with a particular attention to the procedures used to preserve the complexity given by photogrammetric and laser scanning data.
\end{abstract}
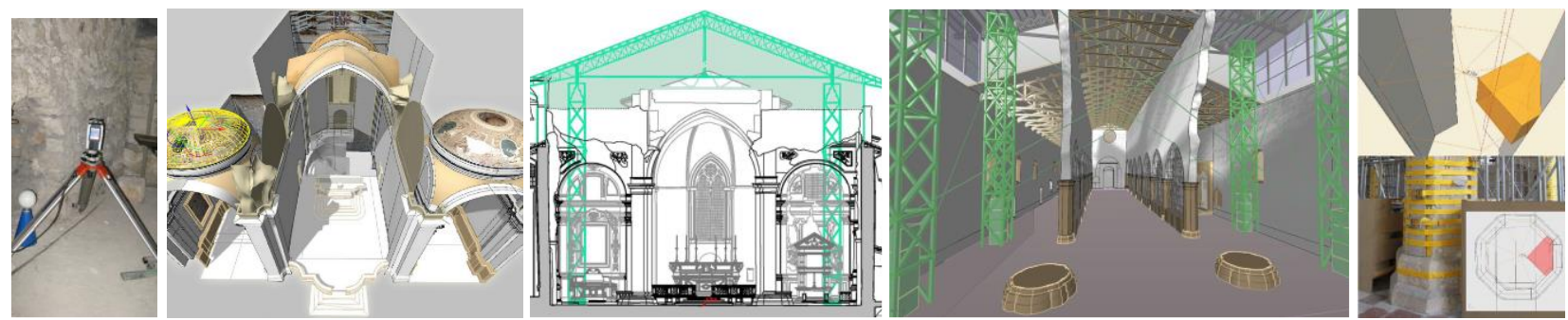

Figure 1. Some images of the BIM of the Basilica di Santa Maria di Collemaggio (L'Aquila).

\section{INTRODUCTION}

The Basilica of St. Maria of Collemaggio in L'Aquila (Italy) was founded at the end of the XIII century and was deeply transformed during the centuries. The monument is the result of a troubled construction history characterized by periodic seismic events that have influenced the structures.

The Basilica was seriously damaged by the earthquake in 2009 . In particular the transept and the central dome collapsed, and the octagonal pillars of the naves were damaged. Immediately after the earthquake the structures were made safe by firefighters and a temporary structure is visible at the moment (see Figure 2 for an UAV picture showing the metal structure in the area of the transept).

The on-going restoration (funded by ENIservizi) involves the "Soprintendenza ai Beni Architettonici e il Paesaggio" of L'Aquila, Politecnico di Milano, University of L'Aquila and Sapienza University of Rome. It has to take into account both the needs of safety and conservation of the architectonic value of the church (Della Torre and Petraroia, 2007).

Survey is part of the restoration project (Addison et al., 2008), needed to carefully evaluate and interpret the geometrical condition of the damaged structures and to create a 3D detailed HBIM (Historical Building Information Modeling) able to manage the phases of analysis, simulation of structural behavior, economic evaluation of the project, and restoration (Della Torre, 2003).
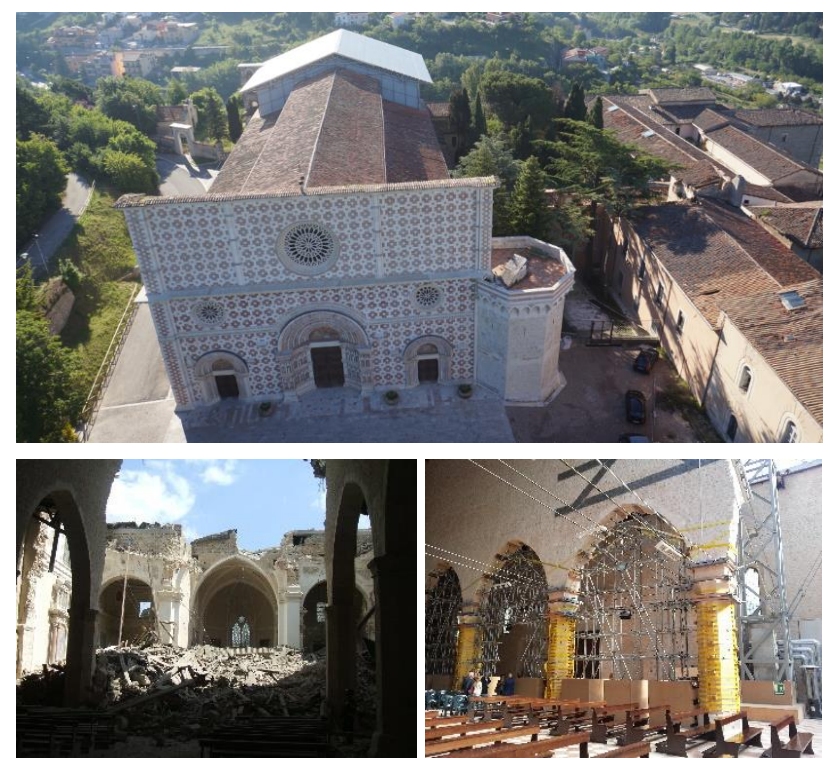

Figure 2. Top: an image of the Basilica acquired with the UAV platform AscTec Falcon 8. Bottom: on the left an image of the transept area immediately after the earthquake in 2009. On the right the consolidation structures to strengthen the octagonal pillars of the naves (2012). 


\section{FROM LASER SCANNING TO HBIM}

The complexity of the survey required the use of the most technologically advanced instruments and techniques. For this reason, both laser scanning and photogrammetric data processing were needed to collect the geometric information co-registered in a robust geodetic network able to provide a stable reference system.

\subsection{Survey of geometries and structures}

The survey was carried out by considering the final goal of the activity, i.e. the creation of a BIM (Eastman et al., 2008; Apollonio et al., 2012; Boeykens, 2011; Boeykens et al., 2011, Murphy et al., 2013a,b) able to reproduce as much as possible the geometric irregularities (Brumana et al., 2014). On the other hand, the complexity and size of the Basilica along with the need to extend the reconstruction in the different parts (e.g. bell tower, cellars, etc.) required a robust geodetic network to fix the datum of the project and to remove deformations during the scan registration and image orientation phases.

For these reasons, the first step of the geometrical survey was the physical materialization and measurement of the geodetic network. The instrument used is a robotic total station Leica TS30 and the final network (Figure 3) consists in 2774 observations and 7014 unknowns. Least Squares adjustment provided a sub-millimetre precision for stations and points with multiple intersections, whereas the laser points (checkerboard targets directly measured during the measurement of network points in order to avoid repositioning errors) have an average precision of about $\pm 1.5 \mathrm{~mm}$. The additional points (target tapes and prisms on fixed nails) were added and measured (i) to strengthen the network and (ii) to provide stable points for future metric applications.

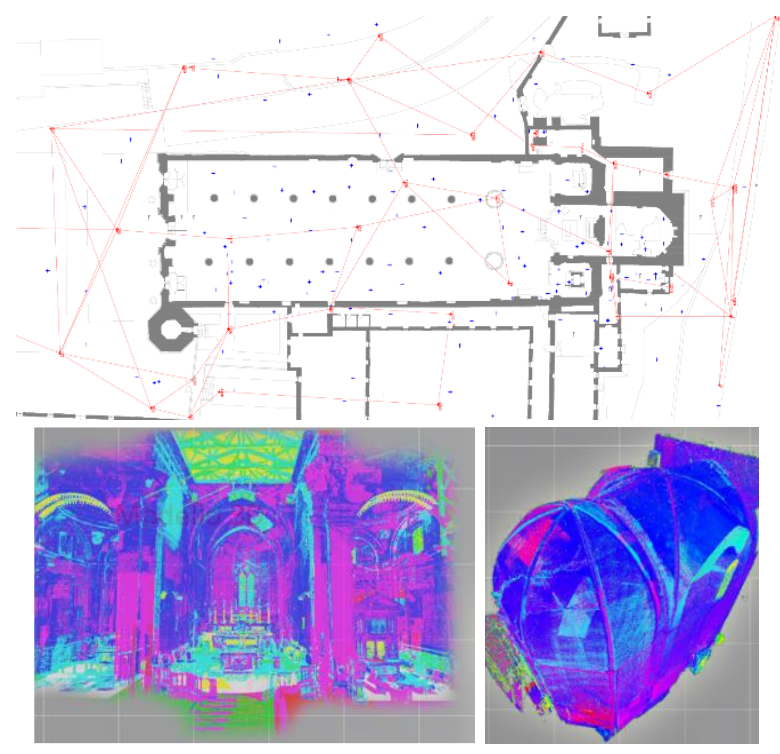

Figure 3. The geodetic network and some pictures of the acquired laser scans.

The laser scanning survey (laser is a fundamental tool for accurate 3D modelling; Chevrier et al., 2009, 2010; Stylianidis et al., 2011; Tang et al., 2011, Oreni et al., 2012b) is made up of 182 scans (roughly 8 billion points) registered by means of checkerboards measured with the geodetic network and spherical targets. The final registration precision was better than $\pm 3 \mathrm{~mm}$, i.e. equivalent to the precision of the laser scanner used (Faro Focus 3D).

\subsection{UAV and close-range photogrammetry}

Image-based methods were used to reconstruct areas where laser data did not provide a sufficient level of detail or where there was a complete lack of data. Different calibrated cameras (Remondino and Fraser, 2006; Cronk et al., 2006) (Nikon D700, Canon Eos 1D Mark IV, Sony NEX-5N) with variable lenses (20, $24,35,50,90$, and $180 \mathrm{~mm}$ for reflex cameras) were used to create orthophotos of the external facades, internal walls, and vaults. The pipeline for image processing followed the typical rigorous scheme of photogrammetric data processing: camera calibration, image orientation, surface extraction and orthophoto generation (Remondino et al., 2008). In some cases alternative procedure based on gnomonic projections (Barazzetti et al., 2013) and perspective rectification (i.e. multiple images collected with a rotating camera fixed on a photo-goniometer and then merged into a single high resolution mosaic) were used to obtain better levels of details.

Orthophotos (see Figure 4 for some examples) with a nominal scale between 1:10 and 1:50 were included in the final HBIM model (and in 2D drawings) to provide a valid support to understand and interpret the structure (e.g. elements like cracks or other structural damages can be easily inspected).

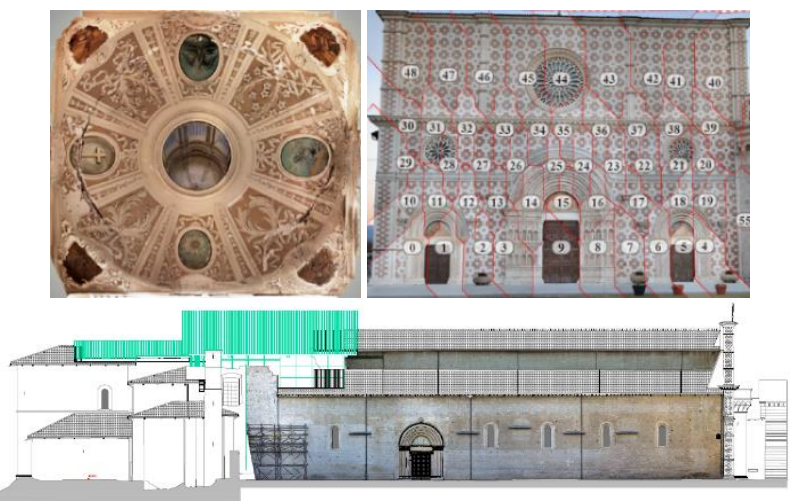

Figure 4. Orthophotos of vaults and facades are fundamental not only for visualization purposes, but also for the inspection of crack patters and interpretation of constructive elements.

The survey of the roof was instead carried with UAV technology (AscTec Falcon 8) and RGB and TIR images. Starting from a photogrammetric block made up of 52 images oriented with ATiPE (Barazzetti et al., 2010) a point cloud was extracted with the MGCM+ algorithm (Previtali et al., 2011). The point cloud allowed the operator to reconstruct the roof structure and provided the geometric model where the images were reprojected to obtain an orthophoto (Figure 5).

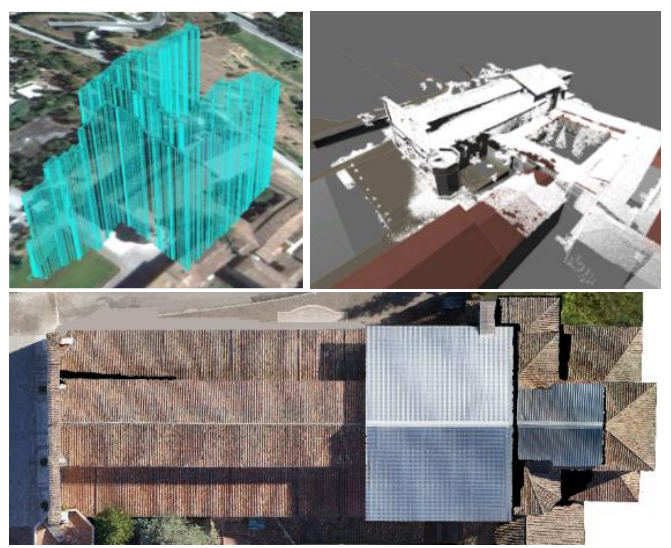

Figure 5. The creation of a true-orthophoto from UAV. 


\subsection{From geometry to HBIM}

Modern digital survey techniques and methodologies allow the acquisition of a large number of three-dimensional data used in architecture, engineering, and archeology. Thus, a wide range of information (especially point clouds) can be directly used in three-dimensional modeling software in order to create BIM models as close as possible to historical buildings and represent their geometry and state of conservation.

Thanks to the interoperability of output formats, it is also necessary to move from a simple geometric model to a new multi-area concept that makes the content model more relevant in specific software for structural and economic analysis (i.e. using WBS - Work Breakdown Structure) or energy efficiency evaluation (i.e. LCA - Life Cycle Assessment, LCM - Life Cycle Management).

The creation of a HBIM for conservation projects (Oreni et al., 2012a) requires the acquisition of the available information, interpretation, and the final modelling of the different structural elements. One of the aims of this research was the analysis of BIM software for the representation of the complexity of the irregular shapes of the elements (such as domes) without losing the details with excessive simplifications resulting in un-useful models for conservation processes.

First of all, the 3D model of the Basilica was divided in its structural elements following the constructive logic of the building: i.e. vaults, wooden elements of the cover, walls, columns, stone ashlars, and decorative elements. The software used were $\odot$ Rhinoceros 4 and 5 and $\odot$ Bentley Pointools: they allowed an accurate modelling of irregular structures, i.e. the out of plumbs of the walls and all the geometric anomalies registered by laser scanner (Figure 6).

Starting from multiple point clouds, ORhino allowed the representation of complex shapes by using not only Boolean operations (i.e. simple extrusions and revolutions on generative axes), but also NURBS (Non Uniform Rational Basis-Splines), i.e. surfaces that arise from a spatial deformation of a grid of square tiled surfaces (patch surfaces) in which the positions of the control points determine the deformation.

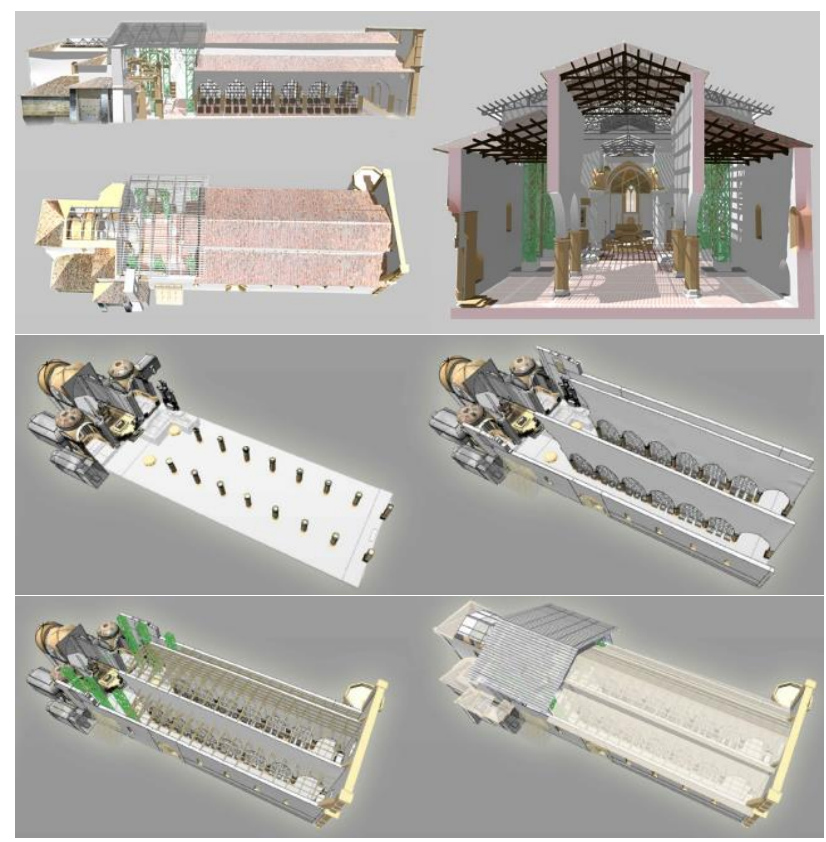

Figure 6. 3D views of the model obtain in CRhino from laser point clouds acquired with a Faro Focus 3D.
The second step was the use of the model and its elements in BIM software, maintaining the parametric data for each shape along with the possibility to add information about the material, the state of conservation, the planned intervention, and so on.

The aim was to overcome the lack of parametric model software (i.e. (O) Graphisoft Archicad and (CAutodesk Revit) for the management of complex and irregular shapes and the issues concerning the standardization of elements in objects and families.

Several experiments were carried out in order to convert the CRhino shapes (NURBS - Piegl and Richard, 1995; Piegl and Tiller, 1997; Farin, 1999) into BIM parametric elements. Finally, a rigorous conversion procedure was developed in order to obtain a complete parametric conversion of all the elements without losing information (Figures 7 and 8: from @Rhino to @Autodesk Revit).

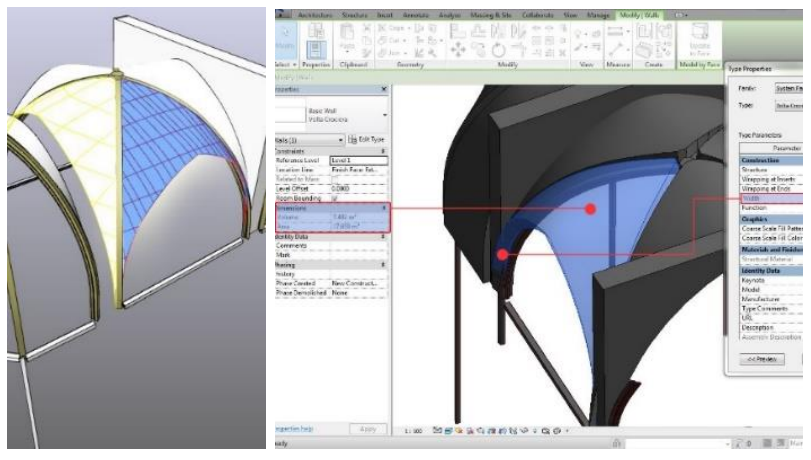

Figure 7. Solid generated with NURBS in ORhino and then parameterized in $\odot$ Revit.
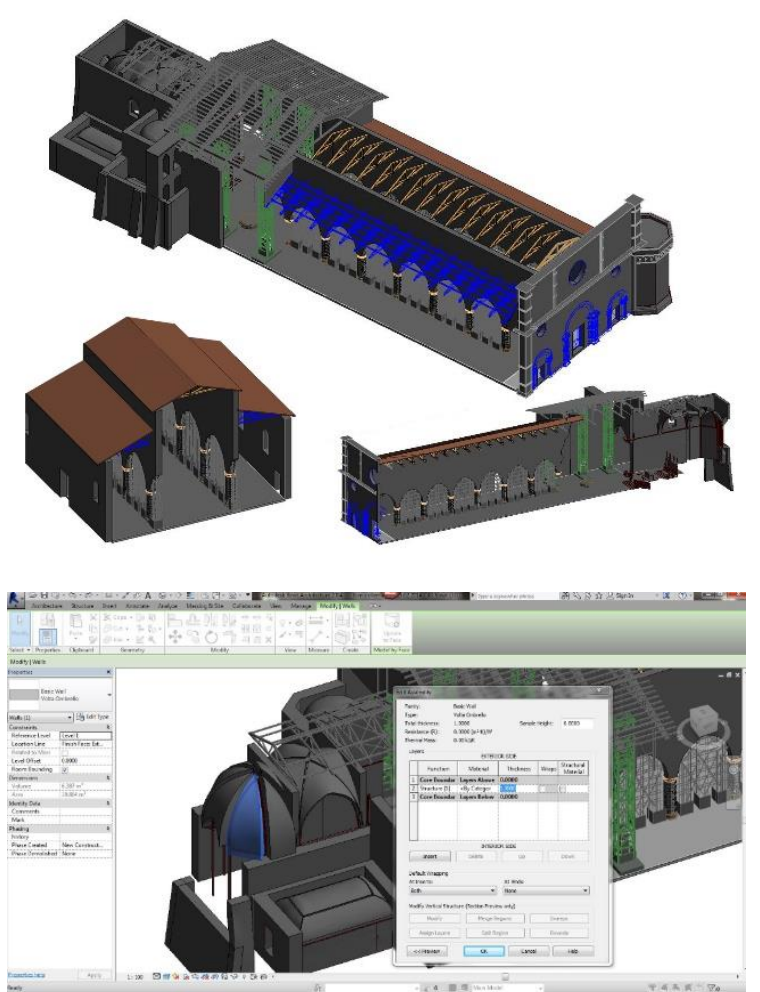

Figure 8. HBIM of the entire Basilica in ORevit: solids from "free form" NURBS in @ Rhino. 


\section{INTEROPERABILITY OF THE HBIM FOR THE MANAGEMENT: INTERCHANGE FORMAT AND PARTING ELEMENTS OF THE MODEL}

Many different experts are working together in the restoration project: engineers, geologists, architects, restores, and historians. Consequently, it is necessary to guarantee the interoperability of the 3D model with the software used by different operators. A lot of time was spent to try out the use of the model in $\odot$ Rhino for structural analysis and simulation and HBIM technology to economically manage the restoration. This means that a deep investigation was necessary to exploit different logics and languages of the various software and to find the quickest method, (using filters, translators, converters and interchange files) to accomplish this task.

In particular, the interoperability between (ORhino and (CMidas (a software for finite element analysis - FEM) was tested in order to use the accurate model and to evaluate project solutions for the new structures and the consolidation of the Basilica. The solids generated in ORhino were discretized by default libraries of structural analysis software (i.e. beam, rod, etc.). Therefore, it was necessary to create solids or surfaces (in (ORhino) oriented towards the discretization mesh system of the software @Midas, that automatically creates grids of coded forms (triangles and quadrilaterals) composed of primitives. These surfaces were imported into the structural calculation software as complex solids, consisting in NURBS surfaces (Figure 9). Their geometric characteristics were maintained during the conversion using ISO 10303 STEP (STandard for the Exchange of Product model data), that is the standard format to ensure the exchange of data between software of different categories (specifically between CAD, CAM , CAE, and PDM / EDM systems).


Figure 9. NURBS solid of the North wall of the Basilica created in Rhino and imported through cad schemes in CMidas for structural simulation.
The economic management required a WBS for the evaluation of the cost of the restoration during the planning phase along with a continuous check to monitor the intervention. This step was based on the subdivision of the @Revit model according to the different restoration actions by using the different structural and decorative elements of the building (Figure 10).

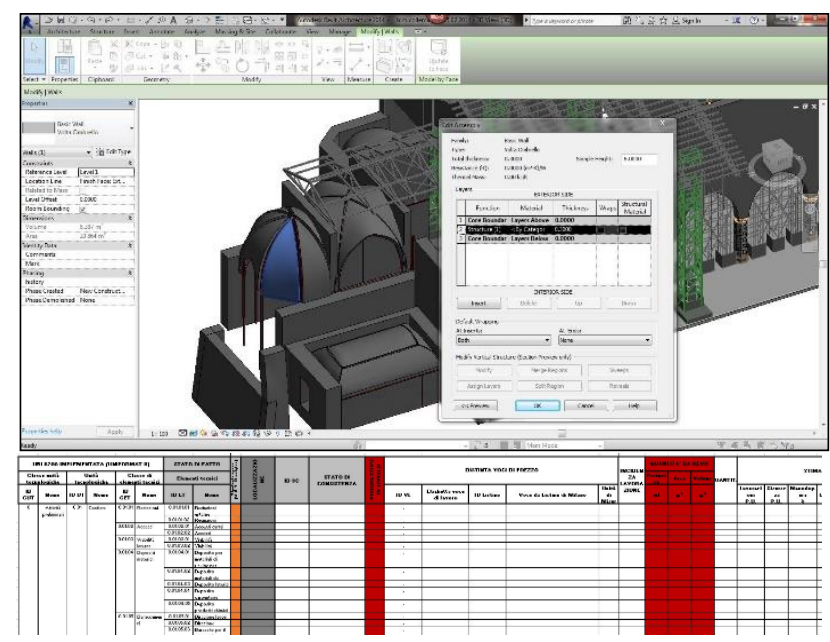

Figure 10.3D CRevit model of the building and WBS to manage the restoration.

\section{HBIM OF THE COLUMNS TO MANAGE THEIR RESTORATION}

A particular attention was paid to the geometrical and constructive analysis of the damaged medieval stone columns of the nave (Figure 11). They were restored in 1970 because of the demolition of baroque's addictions all around the columns. The intervention allowed us to view the medieval structures of the pillars, very damaged and cracked. Moreover, the columns were restored changing broken stones and inserting mortar to give them an acceptable aesthetic aspect without solving many structural aspects. The 2009 earthquake underlined the fragility of the columns because they were seriously damaged. The day after the earthquake firefighters created a thick provisional hoop in order to support the weight of the structure.



Figure 11.3D representation of the stone ashlars of the columns, surveyed using both laser scanner and direct instruments. 
As the aim was to preserve as much as possible the existing columns and their stone elements (in some cases painted), a 1:1 survey of the pillars was carried out by integrating laser scanner data with manual measurements to reconstruct the geometry and arrangement of the blocks in rows.

It is important to mentioned that a preliminary disassemble is not possible to evaluate the exact consistency of the internal part. Therefore, both survey and data interpretation provided a fundamental tool for structural engineers to plan specific interventions.

A two-dimensional representation (scale factors 1:20 and 1:10 of the pillars and their ashlars) was indispensable to map materials, degradation and cracks. This information was insert in the (ORevit 3D model in order to create a database (see Figure 12 and 13 for some details).

The aim of the restoration is to give a more regular column weaving, considering no more than four elements for each course and also renewing the mortar and sealing: the HBIM model allows one to significantly speed up this operation.

In fact it is possible to predetermine the shape of the stone block to be replaced and to transfer the data to the worker that has to extract and cut the stone. The cut will be quickly executed by a numerical control machine on the basis of the data provided. This chain of operations can be simulated in the project in order to optimize the processing cycle to save significant time, which constitutes an important goal of the work.

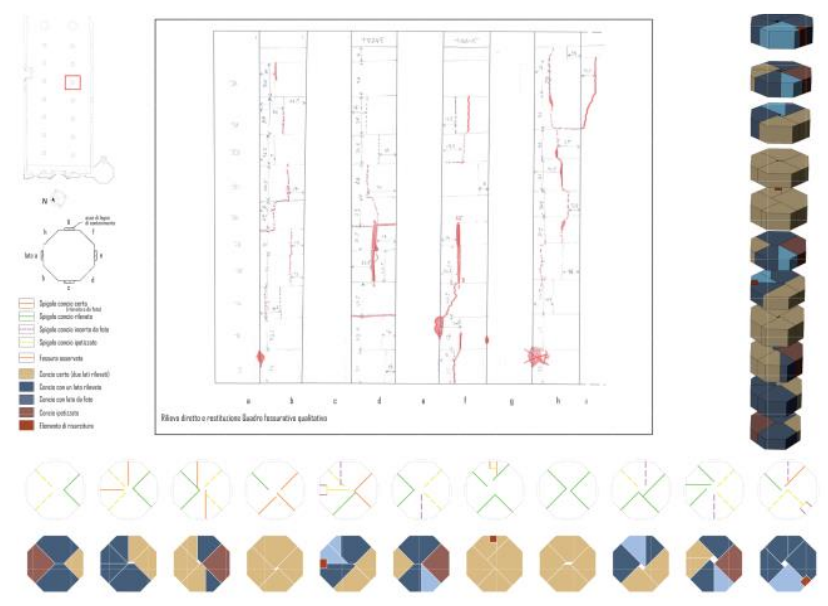

Figure 12. 2D and 3D representations of the columns.

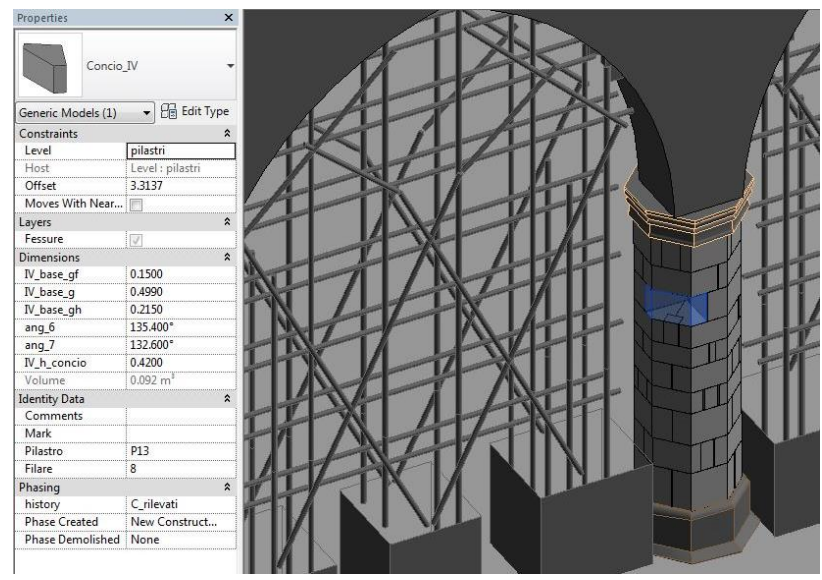

Figure 13.3D detail of the $\odot$ Revit model of the columns and their stone elements.

\section{CONSIDERATIONS AND CONCLUSIONS}

This paper presented the survey and modeling work concerning the Basilica di Collemaggio. The generated HBIM is currently used to support the on-going design project of conservation and intervention of the damaged parts.

The peculiarity of the irregular shapes and their correspondent structures and constructive elements were extremely important and needed a special attention. For example, it is now possible to associate the thickness before an inspection, that can be then updated depending on the different chronological information or other considerations regarding the structural behavior.

The interoperability with the HBIM and other software was also essential to share a common information. For example, in the case of the finite element analysis, the software @Midas and the Step output format allowed one to apply the simplified logic of the FEM approach to a complex historical building, conserving and maintaining the richness of the NURBS results.
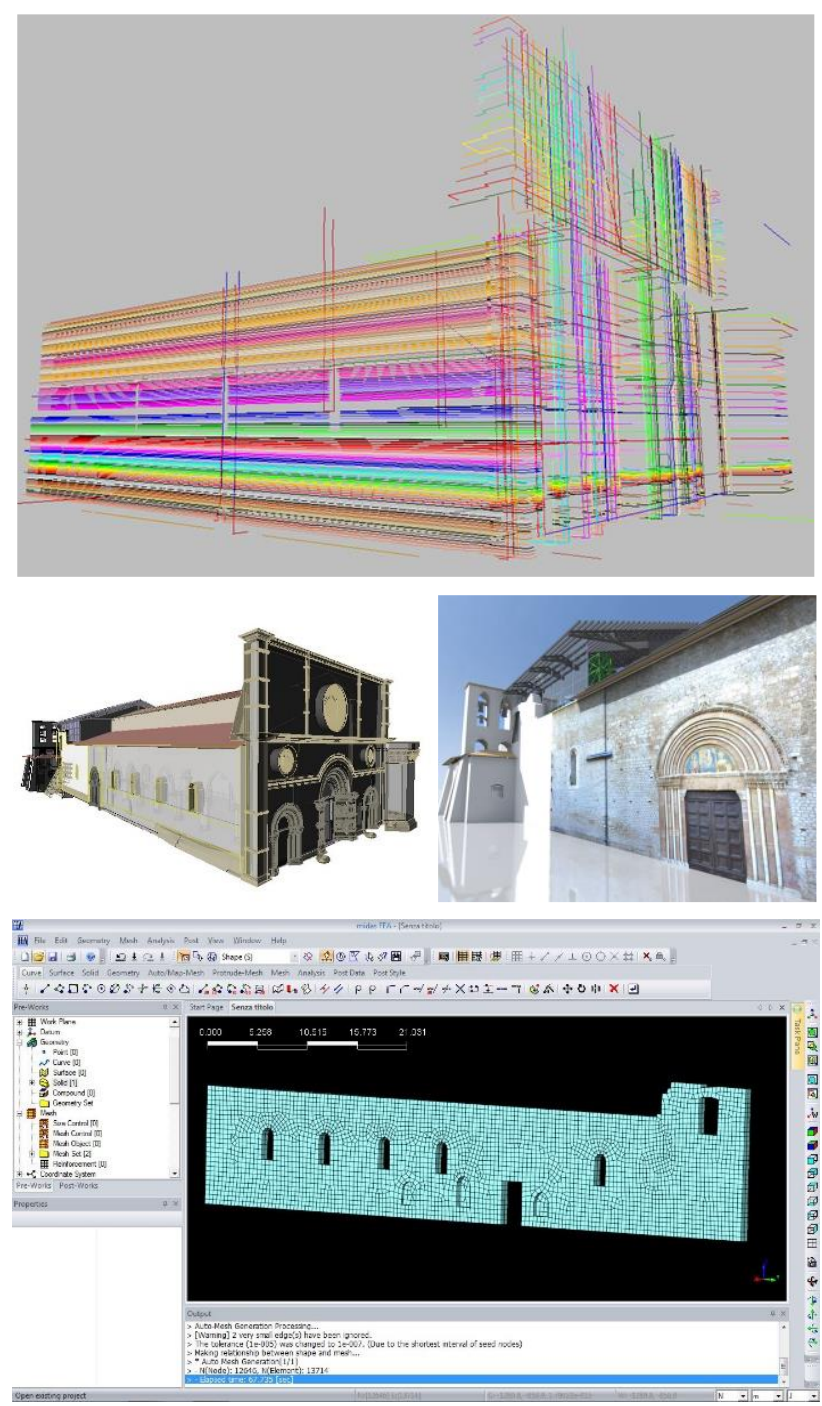

Figure 14. The profiles used to reconstruct the North wall, the HBIM model and its use in $\odot$ Midas for finite element analysis: geometric details modeled with NURBS are preserved.

One of the main challenges for such a complex project was the limiting standardization offered by current BIM technology used to manage simple buildings and constructions. The parametric approach used in this work (Figure 15) is not finalized to generate libraries of objects. The obtained complex objects are instead 
directly associated to (i) the needed information to manage the project of intervention, (ii) the simulation of the different scenario in terms of structural behavior (i.e. column conservation) and (iii) the design of the intervention (i.e. the collapsed central dome and the crusade vaults).

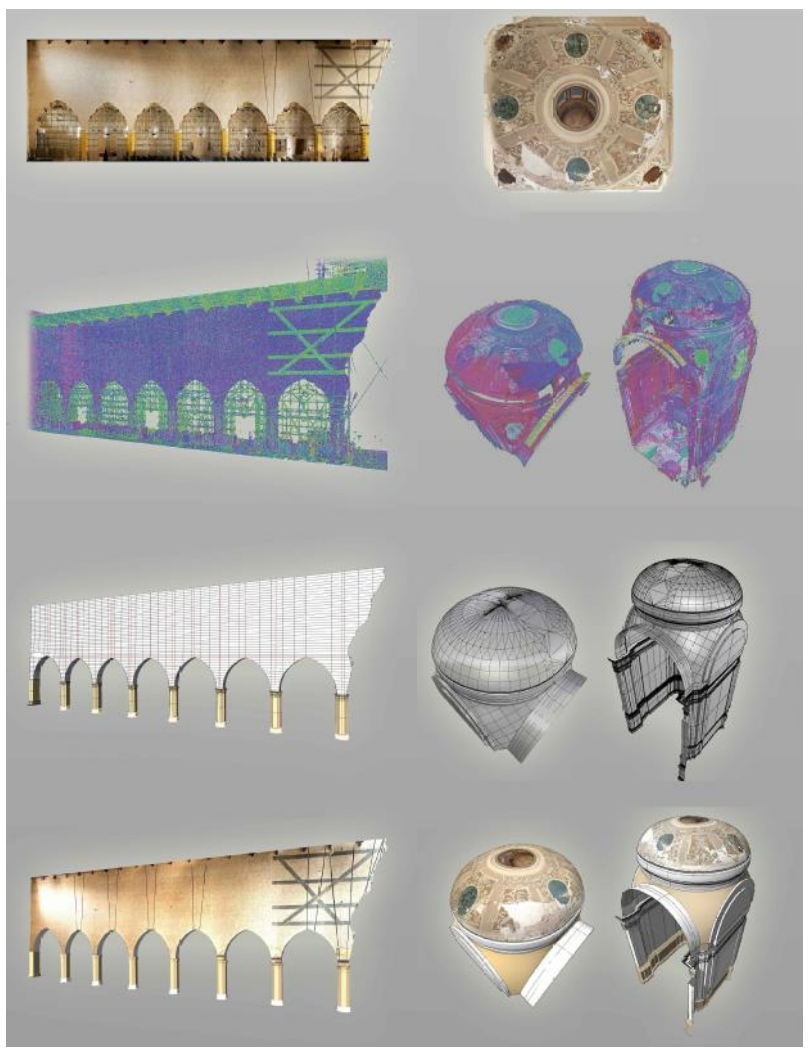

Figure 15. Photogrammetric (orthophotos on top) and laser scanning (point clouds) products are managed in Rhino to obtain detailed NURBS then converted into parametric models following the BIM logic.

Therefore, the BIM logic took into consideration that data management must preserve the complexity (anomalies and the geometric characteristics) of the Basilica. The use of sophisticated modelers (such as @Rhino) allowed one to produce complex entities that are then rigorously converted, integrated and stored within the parametric logic of ORevit. Such process allowed one to manage the shape complexity according to the interpretative logic and models that are at the base of the general purpose of the conservation.

\section{ACKNOLEDGMENTS}

This work was supported by the project "Ripartire da Collemaggio" financed by Eni (www.eni.com).

The authors would like to thank Alberto Franchi, Paola Ronca and Pietro Crespi for the CMidas images and Gianni Utica for the WBS.

\section{REFERENCES}

Addison, A., Santana Quintero, M., Severo, M., 2008. Cultural heritage repositories: Digital Archives for Conservation and Management. In Browsing architecture: Metadata and Beyond. Fraunhofer IRB, pp. 306-317.

Apollonio, F. I., Gaiani, M., Sun Z., 2012. BIM-based modeling and data enrichment of classical architectural buildings. In: SCIRES-IT, 2(2), pp. 41-62.

Barazzetti, L., Remondino, F. and Scaioni, M., 2010b. Orientation and 3D modelling from markerless terrestrial images: combining accuracy with automation. Photogrammetric Record, 25(132), pp. 356-381.

Barazzetti L., Previtali M., Scaioni M. (2013). Stitching and processing gnomonic projections for close-range photogrammetry. Photogrammetric Engineering and Remote Sensing, Vol. 79(6) , pp. 573-582

Boeykens, S., 2011. Using 3D Design software, BIM and game engins for architectural historical reconstruction. CAAD Futures, Liege, Belgium, 6-8 July.

Boeykens, S., Himpe, C., Martens, B. 2012. A case study of using BIM in Historical Reconstruction - The Vinohrady synagogue in Prague. 30th International Conference on Education and research in Computing Aided Architectural Design in Europe, Prague, Czech Republic, 12-14 September.

Brumana, R., Oreni, D., Cuca, B., Binda, L., Condoleo, P., Triggiani, M., 2014. Strategy for integrated surveying techniques finalized to interpretive models in a byzantine church, Mesopotam, Albania. International Journal of Architectural Heritage, 8 (6), pp.886-924.

Chevrier, C., Maillard, Y., Perrin, J.P., 2009. A method for the 3D modelling of historic monuments: the case of a gothic abbey. In: International Archives of Photogrammetry, Remote Sensing and Spatial Information Science, 38 (5/W1), (Cd-rom).

Chevrier, C., Charbonneau, N., Grussenmeyer, P., Perrin, J.P., 2010. Parametric documenting of built heritage: 3D virtual reconstruction of architectural details. International Journal of Architectural Computing, 8 (2), pp. 131-146.

Cronk, S., Fraser, C., Hanley, H., 2006. Automatic metric calibration of colour digital cameras. Photogramm. Rec., 21(116): 355-372.

Della Torre, S., 2003. La conservazione programmata del patrimonio storico architettonico. Linee guida per il piano di manutenzione e consuntivo scientifico. Guerini, Milano.

Della Torre, S., Petraroia, P., 2007. Integration of Maintenance and Management Activities with Authorization Procedures for listed Architectural Heritage. Maintenance Management 2007. Third International Conference on Maintenance and Facility Management. 27-28 September, pp. 87-90.

Eastman, C., Teicholz, P., Sacks, R., Liston, K., 2008. BIM Handbook. A guide to Building Information Modeling for Owners, Managers, Designers, Engineers, and Contractors. Jonn Wiley \& Sons, Hoboken, New Jersey. 
Farin, G.E., 1999. NURBS: from projective geometry to practical use. A K Peters, Ltd., Natick, Massachusetts, 2nd edn.

Murphy, M., McGovern, E., Pavia, S., 2013a. Historic Building Informatio Modelling - Adding intelligence to laser and image based surveys of European classical architecture. In: International Archives of Photogrammetry, Remote Sensing and Spatial Information Science, 76, pp. 89-102.

Murphy, M., McGovern, E., Pavia, S., 2013b. Historic Building Information Modelling: adding intelligence to laser and image based surveys. ISPRS Journal of Photogrammetry and Remote Sensing, n. 76, pp. 89-102.

Oreni, D., Brumana, R., Cuca, B., 2012a. Towards a Methodology for 3D Content Models. The Reconstruction of Ancient Vaults for Maintenance and Structural Behaviour in the logic of BIM management. Virtual Systems in the Information Society. NJ, USA, Milan, Italy, 2 - 5 September, pp. 475-482.

Oreni, D., Cuca, B., Brumana, R., 2012b. Three dimensional virtual models for better comprehension of architectural heritage construction techniques and its maintenance over time. Progress in Cultural Heritage Preservation - Lecture Notes in Computer Science, Heidelberg London New York, (7616), pp. 533-542.

Piegl, L.A., Tiller, W., 1997. The NURBS Book. SpringerVerlag, Berlin, Germany, 2nd edn.

Piegl, L.A., Richard, A.M., 1995. Tessellating trimmed NURBS surfaces. Computer Aided Design 27(1):16-26.

Previtali, M., Barazzetti, L., Scaioni, M., Yixiang T., 2011. An automatic multi-image procedure for accurate 3D object reconstruction. 4th International Congress on Image and Signal Processing - IEEE Conference Record Number 18205, Shanghai, 15-17 October, 5 pages

Remondino, F. and Fraser, C., 2006. Digital camera calibration methods: considerations and comparisons. International Archives of Photogrammetry, Remote Sensing and Spatial Information Sciences, 36(5): 266-272.

Remondino, F., El-Hakim, S.F., Grün, A. and Zhang, L., 2008. Turning images into 3-D models - development and performance analysis of image matching for detailed surface reconstruction of heritage objects. IEEE Signal Processing Magazine, 25(4): 5565 .

Stylianidis, E., Patias, P., Santana Quintero, M., 2011. CIPA Heritage documentation - best practices and applications. CIPA.

Tang, P., Huber, D., Akinci, B., Lipman, R., Lytle, A., 2011. Automatic reconstruction of as-built building information models from laser-scanned point clouds. A review of related techniques. In: Automation in Construction, 19 (7), pp. 829-843.
CAutodesk Revit

http://www.autodesk.com/products/autodesk-revitfamily/overview

\section{CBentley Pointools}

http://www.bentley.com/en-

US/Promo/Pointools/pointools.htm?skid=CT_PRT_POINTOO

LS_B

CMidas

http://en.midasuser.com/products/overview.asp?nCat=353

(C)Rhinoceros

http://www.rhino3d.com/ 